\title{
Formação inicial de professores de química: uma reflexão pedagógica do fazer docente
}

\author{
Paulo Roberto Lima de Souza*; (Aluno do Programa de Pós Graduação em Educação da UFRN, \\ cursando Mestrado Acadêmico) \\ Débora Cristina Oliveira de Santana; (Aluna do Programa de Pós Graduação em Ensino de \\ Ciências Naturais e Matemática, cursando Mestrado Profissional) \\ Josivânia Marisa Dantas. (Professora Adjunta do Departamento de Práticas Educacionais e \\ Currículo do Centro de Educação da UFRN)
}

\begin{abstract}
resumo:
Diversas mudanças no meio econômico, social e inevitavelmente, educacional, impulsionam debates que tem por pauta a concretização de políticas públicas no campo educacional brasileiro. A estruturação dessas políticas bem como as lutas por suas implementações tem forte efervescência na década de 1990 trazendo para o centro do debate questões como a formação docente, inclusão social, melhoramento dos espaços educativos e outras que surgem da urgente necessidade de uma educação para todos e de qualidade. Em meio a tantos aspectos que merecem considerável importância dentro dessas políticas, optamos em discutir, neste trabalho, a formação inicial de professores de química. Nesse sentido, a reflexão aqui proposta objetiva, por meio de referencial bibliográfico, apresentar ponderações sobre a importância da formação inicial de professores de química, bem como o papel que esse novo educador deve assumir frente às demandas sociais, econômicas e educacionais em que os sujeitos de sua prática estão inseridos.
\end{abstract}

pallavras-chave:

Formação inicial; Educação; Licenciatura em Química. 


\section{1- Introdução}

Na década de 1990 as políticas para a educação ampliaram o leque de abrangência das reformas educativas vinculadas ao trabalho na perspectiva econômica da globalização e do ${ }^{1}$ estado mínimo. Aliado a isso se verifica os interesses do Banco Mundial que traz a necessidade de uma educação básica como propulsora do crescimento econômico e redução da pobreza, mas, principalmente, que atenda as transformações que ocorrem no mercado de trabalho.

Nesse contexto se inicia com grande força a difusão da ideologia ${ }^{2}$ neoliberal que postula que o Estado de Bem Estar estaria reduzindo a poupança e os investimentos do setor público, sendo responsáveis pelo fraco desenvolvimento da economia aliada as políticas sociais que canalizavam investimentos de setores produtivos para os improdutivos.

Ainda na década de 1990 o processo de gestação da atual LDB 9.394196 teve importante papel ao intensificar debates relacionados à prática da autonomia pedagógica, administrativa e de gestão financeira como condição para a escola executar, realmente, seu projeto político pedagógico (CARNEIRO, 2014). Assim como debates na área da educação especial, expansão da educação básica, oferta da educação técnica, valorização e formação docente. Destacamos ainda o incentivo à formação de professores em nível superior para atuarem na educação básica, bem como programas de formação continuada para os que já possuíam esse nível de formação.

Ao mesmo passo que regulamentou e institucionalizou pautas de lutas dos educadores brasileiros a 3LDB também deixou lacunas que se apresentam, por exemplo, no financiamento da educação pública que divide os repasses para instituições públicas com a iniciativa privada. Essas medidas buscam atender a agenda neoliberal e captar recursos de organismos internacionais como o Banco Mundial.

Dessa maneira, com base nas estruturas políticas e pedagógicas que deliberam a respeito da formação de professores, em especial a formação inicial de professores de química, propomos apresentar os pontos mais relevantes a esse respeito e apontar reflexões necessárias à construção de práticas educativas que tenham como finalidade a4emancipação do homem.

Conformo o exposto, buscamos referências de autores que discutem a temática da formação de professores de química com a finalidade de refletir sobre o que já está posto e o que é possível acrescentar com outras experiências e diferentes prismas.

Na literatura é possível encontrar os trabalhos de Ana Maria Pessoa de Carvalho que tem uma sólida produção de livros e artigos que discutem a importância da formação inicial e continuada de professores; Otávio Aluísio Maldaner que tem salutar discussão sobre formação de professores, em especial os de química; Bernadete Angeline Gatti que traz em seu livro "Políticas docentes no Brasil: um estado da arte" reflexões em uma perspectiva histórica e pedagógica sobre a temática; Paulo Freire em seu livro "Pedagogia do Oprimido"(1996) que apresenta uma belíssima reflexão a respeito de uma formação para a emancipação do sujeito tendo por base a criticidade e reflexão do papel do homem na sociedade. Destacamos ainda os estudos de autores como SAVIANE, GADOTTI, ECHEVERRÍA e ZANON. Estes autores veem construindo, analisando e discutindo diversos trabalhos que estão intimamente ligados a questões relevantes sobre a formação de professores no Brasil, bem como discutindo esta temática em bancas de dissertações e teses e em eventos científicos.

\section{2- A construção de saberes docentes em formação inicial}

\footnotetext{
${ }^{1} \mathrm{O}$ papel do Estado que era de interventor deveria ser redefinido de forma que passasse de pesado, grande e ineficiente para mínimo no que se refere as responsabilidades sociais sem deixar de ser máximo para o capital, na medida em que libera as livres relações de mercado e favorece o clima para a entrada de investimentos do capital transnacional. (PERONI, 2003)

${ }^{2 \cdot *}$ Será considerado neoliberal toda ação estatal que contribua para o desmonte das políticas de incentivo à independência econômica nacional, de promoção do bem-estar social (WelfareState), de instauração do pleno emprego (Keynesianismo) e de mediação dos conflitos socioeconômicos" (SAES, 2001, p. 82)

${ }^{3}$ Também chamada de Lei Darcy Ribeiro, que foi seu redator.

${ }^{4}$ Conceito de emancipação segundo Freire (1996) implica ter ciência de um processo em que os aspectos crítico-reflexivos, técnicos, humanos/sociais e pedagógicos se façam presentes de forma ativa e desvelada de práticas autoritárias, intuitivas e que destoem da realidade em que o processo educativo se dá.
} 
Em meio à efervescência política vivenciada na década de 1990 temos o fortalecimento do discurso de que a educação é o principal caminho para a melhoria de vida. Na consolidação desse discurso, a escola (o professor) ganha destaque ao ser responsável pelo sucesso ou fracasso das pessoas que são atendidas pelo sistema educacional.

No entanto, é salutar termos a clareza que a educação sozinha não consegue protagonizar mudanças estruturais e em grande escala. Isso quer dizer que aliados a ela precisamos de um tanto de outros direitos, tais como, saúde, moradia, alimentação, respeito, dignidade, segurança, etc., para juntos lutar pela construção de uma sociedade mais igualitária e justa. Sobre isso, Freire faz a seguinte colocação:

Não é possível refazer este País, democratizá-lo, humanizá-lo, torná-lo sério, com adolescentes brincando de matar gente, ofendendo a vida, destruindo o sonho, inviabilizando o amor. Se a educação sozinha não transformar a sociedade, sem ela tampouco a sociedade muda. (FREIRE, 1996)

Nesse sentido, devemos ter a compreensão que a educação sozinha não pode fazer muito, no entanto, sem ela os caminhos ficarão bem mais tortuosos e desiguais. Com isso, compreendemos que a educação se configura como um direito fundamental, mas que deve estar atrelado a outros direitos, também fundamentais, para juntos traçar caminhos de crescimento ético, humano e profissional.

Compreendendo o papel que a educação e, em especial, o professor assumem na conjuntura de sociedade que estamos inseridos, a formação do educador que poderá atuar como agente de mudanças, e os saberes que formam sua base para o exercício da prática educativa devem se apropriar das outras dimensões do ensino, como o profissionalismo, formação humana e sua epistemologia enquanto peças fundamentais no processo de construção coletiva do conhecimento (VIGOTSKY, 2001).

Na perspectiva de formação de professores, é de todo conveniente ressaltar que temos como ponto de referência para essa discussão o papel da escola nas sociedades contemporâneas e, em decorrência, o papel dos professores nesse contexto (Gatti, 2011).

Ainda compactuando das ideias apresentadas por Bernadete Angelina Gatti, compreendemos que o papel tanto da escola como também dos educadores tem seu núcleo balizado pela árdua tarefa de

Ensinar, ao mesmo tempo formando e propiciando o desenvolvimento de crianças e jovens, uma vez que postulamos que, sem conhecimento básico para interpretação do mundo, não há verdadeira condição de formação de valores e de exercício de cidadania, com autonomia e responsabilidade social(GATTI, 2011, p. 89).

Pontuamos ainda que a cada momento histórico vivido temos um modelo de sociedade e indissociavelmente educacional requerido para atender as necessidades daquele momento em específico. Atualmente os discursos científico, econômico e educacional defendem a formação de profissionais da educação capazes de conduzir uma formação de qualidade e que consiga suprir as necessidades de um mercado de trabalho e sociedade dita globalizada. Nesse sentido,

Todo planejamento educacional, para qualquer sociedade, tem de responder às marcas e aos valores dessa sociedade. Só assim é que pode funcionar o processo educativo, ora como força estabilizadora, ora como fator de mudança. Às vezes preservando determinadas formas de cultura. Outras, interferindo no processo histórico, instrumentalmente. De qualquer modo, para ser autêntico, é necessário ao processo educativo que se ponha em relação de organicidade com a contextura da sociedade a que se aplica. (FREIRE, 1996) 
Dessa forma, o profissional que assume o papel de mediador na construção de conhecimentos é o educador, no que tange toda a educação 5 formal.

Com relação ao papel assumido socialmente por aqueles que escolhem a docência, IMBERNÓN (2009) atenta que "a formação inicial de professores se caracteriza como processo de construção da significação da profissão docente, pois representa a socialização profissional, atribuindo o conhecimento básico ao futuro professor”.

Ainda sobre o papel docente

É importante entender que o objetivo geral do professor é a promoção de uma atitude criativa, crítica e ilustrada, na perspectiva de construir coletivamente a aula e em geral os espaços de aprendizagem. Em tal "construção coletiva" trata-se, mais que manejar informações, de articular conhecimentos, argumentos e contra-argumentos, baseados em problemas compartilhados, nesse caso relacionados com as implicações do desenvolvimento científico-tecnológico (Bazzo, von Linsingen e Pereira, 2003: 149).

Esse profissional assume fundamental tarefa na nossa sociedade e quando remetemos o papel do professor na formação de outros professores, este trabalho deve estar alinhado a ideais que instrumentalizem os futuros docentes a atuarem como investigadores/pesquisadores, eternos estudantes e provocadores no processo de (re) construção do conhecimento.

Nesse sentido, compreender o papel da educação pressupõe pensar algumas questões: Como se dá a formação dessas pessoas enquanto docentes? Em que medida esta formação irá proporcionar o exercício de uma prática pedagógica exercida com qualidade, consciência e reflexão?

Para buscar caminhos que apontem para as respostas a estes questionamentos, precisamos desatrelara prática docente a simplicidade de um "dom" ou tão pouco acreditar que existe uma receita pronta para seu exercício. Ser professor exige formação, estudos e muita dedicação para atuar enquanto mediador na prática de construção do conhecimento. Sobre isso, Echeverría e Zanon (2010, p. 126), discorrem que

A questão da formação docente não será convenientemente encaminhada se insistirmos na busca alquímica de panaceias pedagógicas. Não há duvida de que o professor deve ser um profissional competente, mas não há uma "estrada real” para alcançar esse desiderato. As instituições formadoras do docente têm de ver nessa variedade o ponto de partida para formular suas propostas.

Nesse sentido, acredita-se que a experiência prática embasada pela formação teórica, as duas caminhando juntas, poderão proporcionar ao futuro professor mais seguranças e subsídios para atuar como mediador no processo de construção do conhecimento de outras pessoas.

Maldaner (2006) em seu livro "A formação inicial e continuada de professores de Química” trás importantes debates relacionados ao fazer docente, bem como a sua preparação para o exercício laboral. Queremos ressaltar o destaque dado pelo autor a superação do modelo $3+1$, como também contagiar os cursos de licenciaturas e seus professores com o entendimento que todas as disciplinas ministradas, mesmo as específicas, devem preparar os estudantes para a docência.

Sobre isso Schnetzler (2003, p. 14) enfatiza que,

A grade curricular da maioria dos cursos de licenciatura manifesta e enfatiza dois caminhos paralelos, que não se aproximam sequer, um do outro, durante vários semestres, mas que não vão se cruzar e se articular em disciplinas de natureza tal como Prática de Ensino, a Didática Específica e/ou de Instrumentação para o ensino. Isso significa que as disciplinas de conteúdos específicos, propriamente ditos, seguem seu curso independente e isolada das disciplinas pedagógicas e vice-versa.

\footnotetext{
${ }^{5}$ Deixamos claro que não é somente na escola que o processo educacional acontece. Esse processo pode se dar de forma informal (em casa, com familiares, com amigos, etc.) ou não formal (igrejas, grupo de escoteiros, associações, etc.)
} 
Nessa perspectiva, o modelo formativo alicerçado nessas práticas deixa de lado o diálogo ${ }^{6}$ extremamente profícuo que deveria acontecer entre as disciplinas que atuam, ou pelo menos deveria atuar na formação de professores, cedendo o lugar para um destoante processo na formação dos novos educadores.

Corroborando com as palavras Schnetzler, Maldaner (2006, pg. 45) enfatiza que "As universidades têm tido dificuldades de superar esse fosso que separa a formação pedagógica da formação específica no campo do conhecimento em que vai atuar”.

Em linhas gerais, estes autores nos trazem ao debate as fragilidades apresentadas ao trabalhar separadamente disciplinas específicas das pedagógicas, visto que, o curso como um todo deve formar professores.

Ao tentar romper este modelo algumas universidades vêm tecendo frutíferos debates nesse campo e obtendo resultados positivos, na medida em que implementam em sua estrutura curricular estágios de regência paralelos a formação específicas, bem como outras disciplinas que discutem as políticas públicas da educação e preparam os alunos para serem docentes de um sistema menos estranho.

Porém, enquanto as disciplinas específicas não assumirem seu importante papel na formação de professores e carregar essa obrigação juntamente com as disciplinas pedagógicas o vácuo continuará presente e reforçará uma formação cheia de lacunas.

Ao tangenciar nossa discussão para formação de professores especificamente de Química encontramos em Ostermann, Schnetzler e Silva (2001 apud ECHEVERRÍA e ZANON, 2010) a concepção que a maioria dos cursos de licenciatura no Brasil ainda não superaram o modelo instituído em 1962, o chamado 3+1: três anos de formação técnica centrada no aprofundamento do conhecimento específico e mais um ano voltado para as disciplinas pedagógicas.

Nesse modelo formativo, ainda não superado de forma satisfatória dentro das academias brasileiras, os discentes vivenciam uma formação fragmentada entre teoria e prática, como se estivem recebendo duas formações diferentes. Isso implica, em grande medida em extremas dificuldades para iniciar as atividades laborais, visto que passaram mais da metade de seus cursos apenas no papel de aluno e não experimentando a tarefa docente, objetivo final do seu curso.

Por este viés retomamos o que discutimos no inicio deste trabalho e evidenciamos que a atual conjuntura social em que estamos inseridos rejeita um professor meramente técnico e desprovido de uma formação pedagógica que o instrumentalize para trabalhar conceitos, fórmulas e equações químicas de maneira que os seus alunos consigam associar a empregabilidade de certos conceitos/conhecimentos específicos associados à sua vida real.

\section{3 - Últimas considerações}

É perceptível que precisamos superar, ainda mais, antigos modelos de educação em que os professores eram formados apenas tecnicamente e distantes de um posicionamento crítico e reflexivo.

Modelos estes que ainda trazem um forte ranço de um processo histórico, em grande medida, aristocrata, militar, Teylorista e voltado, para as necessidades de um mercado de trabalho banhado no modelo capitalista. No entanto, esse modelo pragmático e mecânico de mediar o processo formativo vêm sendo fortemente refutado dando espaço para o diálogo enquanto processo educacional do sujeito livre.

A luta para superação de tais modelos, bem como um olhar mais digno e respeitoso para os profissionais da educação não pode cessar. Nesse sentido, pensamos no espaço universitário enquanto lócus para a formação de professores como mola mestra responsável por propiciar a

${ }^{6} \mathrm{O}$ diálogo é o encontro dos homens, mediatizados pelo mundo, para pronunciá-lo, não se esgotando, portanto, na relação eu-tu. Não é possível o diálogo entre os que querem a pronuncia do mundo e os que não querem; entre os que negam aos demais o direito de dizer a palavra e os que se acham negados deste direito. É preciso primeiro que, os que assim se encontram negados no direito primordial de dizer a palavra, reconquistem esse direito, proibindo que esse assalto desumanizante continue (FREIRE, 1996). 
formação de professores que estejam comprometidos com a emancipação de seus aprendizes dentro de um processo de construção do conhecimento coletivo, participativo, humanizante e libertário.

Nessa perspectiva, com base em nossas reflexões e nas dos autores que foram discutidos no decorrer deste trabalho, entendemos ser possível formar profissionais comprometidos com as ideias aqui defendidas e com isso buscar alternativas que impactem a educação básica brasileira de forma positiva. Para que isso se concretiza a parceria entre universidades e instituições públicas de educação básica devem ser estreitadas e políticas públicas de formação inicial e continuada de professores sejam algo possível para os profissionais que estão diariamente no “chão" da escola publica no nosso país. 
Initial training of chemistry teachers : pedagogical reflection of teachers do

\begin{abstract}
:
Several changes in the economic, social and inevitably, educational, drive debates whose agenda the implementation of public policies in the Brazilian educational field. The structuring of these policies as well as the struggles for its implementations have strong effervescence in the 1990s bringing to the center of the debate issues such as teacher training, social inclusion, improvement of educational spaces, and others that arise from the urgent need for education for all and quality. Amid so many aspects merit full importance within these policies, we have chosen in this work discuss the initial formation of Chemistry teachers in specific and pedagogical bases. To meet this proposition sought a theoretical reference that this account of subsidizing our discussion and support us in some reflections that are made throughout the text and with more emphasis in our final considerations. In this sense, this work aims, through bibliographic references, present reflections on the importance of initial training chemistry teachers, and the role that this new educator should take forward the social demands, economic and educational in the subjects of their practice are inserted.
\end{abstract}

Keywords:

Initial training ; education; Degree in Chemistry.

\title{
4 - Referências bibliográficas
}

BRASIL, Ministério da Educação. Lei 9.394/96. Lei de Diretrizes e Bases da Educação Nacional. Brasília: MEC, 1996.

BAZZO, W. et al. [eds.] (2003), Introdução aos estudos CTS (Ciência, tecnologia e sociedade), Madrid: OEI.

CARNEIRO, Moaci Alves. LDB fácil: leitura crítico-compreensiva, artigo a artigo. 22. ed. Petrópolis, RJ: Vozes, 2014.

ECHEVERRIA, A.R.; ZANON, L.B. (orgs.). Formação Superior em Química no Brasil: práticas e fundamentos curriculares - Ijuí: Ed. Unijuí, 2010.

FREIRE, P. Pedagogia do Oprimido. 17ª Ed. São Paulo: Paz e Terra, 1996.

GADOTTI, Moacir. Educação popular, educação social, educação comunitária. Conceitos e práticas diversas, cimentadas por uma causa comum, 2013. http://www.proceedings.scielo.br/pdf/cips/n4v2/13.pdf Acesso em 03/06/2015.

GADOTTI, M. Perspectivas atuais da educação. Escola: Espaço de Formação dos Profissionais da Educação, Araras - SP, p. 209-215, 2006.

GATTI, Bernadete Angelina. Políticas docentes no Brasil: um estado da arte/ Bernadete Angelina Gatti, Elba Siqueira de Sá Barreto e Marli Eliza Dalmazo Afonso André. - Brasília: UNESCO, 2011. 
IMBERNON. F. Formação Docente e Profissional: formar-se para a mudança e a incerteza. 7. ed. São Paulo, Cortez, 2009.

MALDANER, O. A. A formação inicial e continuada de professores de química professor/pesquisador. 3ed. - Ijuí: Ed. Unijuí, 2006.

PERONI, V. Breves considerações sobre a redefinição do papel do Estado. In: Políticaeducacional e papel do Estado: no Brasil dos anos 1990. São Paulo: Xamã. 2003. p. 21-134

SAES, D. A política neoliberal e o campo político conservador no Brasil atual. In: República do Capital: capitalismo e processo político no Brasil. São Paulo: Boitempo, 2001. p. 81-105.

SAVIANI, D. Pedagogia e formação de professores no Brasil: vicissitudes dos dois últimos séculos. In: IV Congresso Brasileiro de História da Educação, 2006, Goiânia. Anais do IV Congresso Brasileiro de História da Educação, 2006. v.CD-Rom.

SCHNETZLER, Roseli P. Pesquisa em Ensino de Química: sua conceitualização, seu desenvolvimento e sua importância na formação de professores, 2003. Programa de pósgraduação em educação - UNIMEP.

VIGOTSKY, L. S. A construção do pensamento e da linguagem. Tradução de Paulo Bezerra. São Paulo: Martins Fontes, 2001. 